\title{
Newborn Blood Pressure
}

National Cancer Institute

\section{Source}

National Cancer Institute. Newborn Blood Pressure. NCI Thesaurus. Code C87105.

The systolic and diastolic blood pressure of the newborn upon examination; the normal range of the systolic blood pressure is 60 - 90, while the normal range of the diastolic blood pressure is $20-60$. 